\title{
Cultivation of Intercultural Communicative Competence under Higher Vocational English Teaching Environment
}

\author{
Li Liu \\ Tianjin Vocational Institute, Tianjin, 300410, China
}

\begin{abstract}
Keywords: Intercultural communicative competence, Higher vocational college students, English learning, Cultivation strategy
\end{abstract}

\begin{abstract}
Intercultural communication refers to the communication process between people of different cultural background. Due to the progress of transportation means and development of communication means, people from different country, race and nationality can contact and communicate with each other frequently and the intercultural communication draws great attention increasingly. The higher vocational education, as the subject of cultivating applied and skilled talents, should adapt to the development of times and social demand and the higher vocational foreign language education is not only the cultivation of language competence, but also the cultivation of intercultural communicative competence.
\end{abstract}

\section{Introduction}

"Intercultural communication” was first presented by American anthropologist Edward T. Hall in his The Silent Language published in 1959, which was commonly regarded by the academic circles as cornerstone of intercultural communication. The intercultural communication first emerged in the United States, which was a country of immigrants with cultural shock. The immigrants from all parts of the world emphasized and maintained their own culture, thus forming the multicultural pattern of the United States. Then, the intercultural communication drew the attention of American scholars of people from all walks of life. The research of intercultural communication in China started in the 80s, which was late. It was a new discipline in China, but it developed rapidly. From the discipline orientation, the intercultural communication research in China had been always closely related to the research with regard to foreign language teaching. In the early 1980s, He Daokuan, English professor of Shenzhen University, first introduced this new discipline on the academic journals. Subsequently, a large number of foreign language teachers published articles to introduce the foreign intercultural communication research status, relation between culture and language and cultivation of intercultural communicative competence. The first intercultural communication monograph wrote by Chinese scholar, namely, Guan Shijie's Intercultural Communication: Knowledge of Improving the Foreign communicative competence, was published in 1995; then the 1st Intercultural Communication Seminar was held in Harbin and the nationwide intercultural communication research organization China Intercultural Communication Association - was established in the same year. In the next 20 years, the research developed rapidly, many important research achievement were made and many theses and works involved the research of vocabulary, pragmatics, way of expression and other language communication and non-language communication as well as how to integrate the cultural contents in the teaching and other aspects. Entering the 21st century, the research scope of intercultural communication is expanded continuously to intercultural management, intercultural training, acculturation, cultural comparison between different nationalities and other fields with regard to mass media.

\section{Intercultural communicative competence}

Recently, with the increasing foreign communication, the intercultural communication becomes frequent. In addition, with the continuous deepening of the understanding of the relationship between language, culture and communication, the research on intercultural communication draws more and 
more attention. Many experts and scholars have studied and defined the intercultural communicative competence (ICC), for example, the three-factor theory (motivation, knowledge and skill) put forward by Spitzberg and Cupach (1984) still has influences today, in which motivation refers to the desire of communicating with others, knowledge refers to the awareness and understanding of communication, and skill refers to the competence of communication. Belay (1993) summarizes the research of predecessors and describes the intercultural communicative competence from three aspects: emotional perspective - intercultural sensitivity; cognitive perspective - intercultural communication awareness; behavior perspective - intercultural alertness. Lustig and Koester (2007) think context, appropriateness and effectiveness as well as knowledge, motivation and behavior constitute the intercultural communicative competence.

Chinese research scholars give some new elements to the research of intercultural communicative competence. The intercultural communicative competence is mainly studied from three perspectives: emotional, cognitive and behavior. The intercultural communicative competence is a comprehensive system, including cultural awareness, cultural knowledge, communication practice and other aspects, for which there are specific requirements. Professor Wen Qiufang (2002) proposes that the intercultural communicative competence includes communicative competence and intercultural competence, in which the communicative competence refers to the "language, pragmatic and strategic competence" and the intercultural competence refers to the "sensitivity, tolerance and flexibility". Specifically, the intercultural communicative competence must be based on the language competence, which does not only include the understanding and mastering of language forms and knowledge, but also include the selection of proper form and meaning at the different occasion, that is, pragmatic competence. The strategic competence refers to the competence of using various means to solve the problems in the language communication, such as explanation and description with synonyms. Based on this, the intercultural competence should be cultivated. This is a progressive process, in which the cultural difference should be realized and the sensitivity to the cultural difference should be cultivated and then the culture of others can be understood and tolerated so as to flexibly use the communicative strategy to realize effective communication. At the same time, it must be realized that the intercultural communication is not to abandon the customs and values and even national culture, but to understand others in the communication and keep consistent in recognizing and handling the problem so as to achieve better cooperation. These theories provide basis for the cultivation of students' intercultural communicative competence in higher vocational English teaching.

\section{Cultivation of intercultural communicative competence under the English teaching environment of higher vocational education}

National Outline for Medium- and Long-Term Program of Education Reform and Development (2010-2020) issued by the State Council in 2010 proposed to "cultivate a large number of international talents that have international vision, know the international rules and have the competence of participating in international affairs and competition”. Thus, it is clear that the foreign language education is not only to cultivate the language competence, but also include the improvement of intercultural communicative competence. For this purpose, many universities have taken corresponding measures and conduct English teaching reform so as to better implement the requirements of "vigorously cultivating students' intercultural communicative competence". The higher vocational education,as the subject of cultivating applied and skilled talents, should adapt to the development of times and social demand, focus on cultivating students' intercultural communicative competence and improve students' comprehensive quality and competence.

The cultivation of intercultural communicative competence is a practical, complicated and long-term work. According to the features of higher vocational English teaching and students' learning, the strategies of cultivating the intercultural communicative competence are put forward as follows: 


\section{Use fundamental public English course to enhance the language competence}

The language competence is the foundation and core of communicative competence. The higher vocational students' language competence is low, so the higher vocational colleges set up the fundamental public English course for at least two semesters. The teacher and students should make full of the course, in which the teacher should teach students the fundamental knowledge of English, enhance the basic grammar and vocabulary, cultivate students' daily speaking and listening skills and improve the basic language communication application competence. At the same time, the teacher should introduce the English background knowledge during teaching, for instance, in case of western diet, the teacher should introduce the relevant the western food culture and table etiquette. The teacher should also guide the pragmatic competence, such as politeness principle and conversational cooperative principle so as to give enlightenment to students' intercultural communication awareness.

\section{Use English quality course to cultivate the intercultural sensitivity}

The intercultural sensitivity is the precondition of improving the intercultural awareness so as to conduct effective intercultural communication and also the starting point of improving the intercultural communicative competence. In the higher vocational English teaching, the students should be guided to positively identify the exotic culture, have correct understanding and emotional attitude towards the exotic culture and improve the intercultural sensitivity so as to improve the intercultural awareness. To enhance the cultivation of the comprehensive quality of modern talents, the higher vocational colleges set up humanistic quality course and some expansive courses in English teaching, such as Introduction to British and American Culture, Appreciation of British and American Culture, Introduction of English Background Knowledge, Appreciation of English Movies and Learn English by Listening Songs etc. These courses should arouse the students' interest in exotic culture so as to enhance their sensitivity to cultural difference. The teacher should look up more data, integrate the course resource and enrich the course content and teaching forms by modern teaching means during teaching. While introducing the related knowledge, the teacher should also remind the students of the various cultural factors in the course, for instance, the teacher can ask the students to carefully study the peculiar language of character in the novel and watch the body language of characters in the movies as well as customs and values and symbolic meaning in the lyrics, and to discuss their difference with our language, culture and values, so as to enhance the students' sensitivity to the intercultural communication and cultivate their intercultural awareness through comparative analysis.

\section{Use Professional English course to improve the intercultural communication strategy}

The higher vocational education aims at cultivating the first-line applied talents in production, construction, management and service and their major setup is based on the vocational technical position group. The Basic Requirements for English Course Teaching of Higher Vocational Colleges (Discussion Draft) formulated by Teaching Guidance Committee clearly points out that "the higher vocational English teaching is divided into two stages: foundation stage and industry stage”. Many higher vocational colleges set up the industrial or professional English course. These vocational English courses have new course setup and use the teaching materials with rich content, wide topics and diversified culture, in which the contents mainly involve many real intercultural communication scene and context, such as international liaison, foreign guest reception etiquette, international business negotiation, foreign enterprise internship and foreign enterprise interview, which are a good supplementation to the cultivation of students' communicative competence, vocational competence and intercultural communicative competence. The teacher can make use of role playing, case teaching, comparative analysis and other teaching methods, which cannot only make the English communication in the working process and business activity link to students' future workplace, but also is effective to cultivate students' pragmatic competence, communication strategy use competence and intercultural communication strategy.

Use course assessment mean to enhance the application of intercultural communication

The course assessment is an important way to check the effect of course reform. The course mode reform must affect the formulation of assessment standard and method. At present, English teaching 
evaluation focuses on process evaluation because it is not scientific to assess the student's learning effect just by the scores of an examination paper. Based on the written examination, the spoken English test is added and attention is also paid to students' learning process, which is the direction of the course assessment reform of many higher vocational colleges. For example, students are divided into groups in a spoken English test, in which some members act as the interviewer of foreign enterprise and some members act as the interviewee to complete the interview scene. The method that completes and shows a project by group makes students really practice by simulating the real communicative environment, which does not only exercise students' language use competence, but also exercise their use of high-level communication strategy, such as proper change of topic, solving of conflict humorously. In particular, the communication strategy is used in the simulated intercultural communication process, which is a good way to improve and enhance the intercultural communicative competence.

Use information resources to open a new way of cultivating the intercultural competence

With the continuous upgrading and progress of computer network technology, it plays an more and more important role in assisting in the teaching. It is not only the learning tool and resource base for the contemporary educational world and its strong communication interaction function provides a wide opportunity for the language learning and practice, which is a great advantage for the organic combination of language learning and cultural learning advocated by the foreign language education world. The online intercultural communication has been reachable and the use of Internet provides a wide space and possibility for the intercultural communication, in which MSN, QQ, ICQ, Weibo and Wechat can enable people to have multiple communication methods. The communication in the network world is somewhat different from that in the realistic world, but the main components language, culture and communication - are still indispensable. The language or non-language communication of two people of different cultural identity through network involves the matter of intercultural communication. If the teacher and students can fully realize this and then conduct scientific research and design some tasks related to English learning, it will provide great possibility for the intercultural English learning as well as massive resources and new way for cultivating the intercultural competence.

\section{Conclusion}

At present, the politics and economy are increasingly integrated in the world and the foreign communication in China has penetrated into politics, economy and trade, culture, science and technology, education, sports, tourism and other aspects. In the frequent foreign communication, how to treat the foreign culture and maintain the fine traditions of the own culture and how to conduct successful communication and exchange with people of different culture require to improve the intercultural communicative competence urgently. How the higher vocational colleges give full play to their advantages, and use English teaching to improve students' intercultural communicative competence and cultivate the modern talents required by the society and how the English teachers broaden their horizon and enhance their cultural quality are to be further studied by educators.

\section{Acknowledgments}

This paper is the phasing research achievement of "Twelfth Five-Year" Plan Education Science Subject "Research on Working Process-based Higher Vocational English Teaching Mode and Evaluation System and Practice” of Tianjin Higher Education Association, project number: 125y113, project leader: Liu Li.

\section{References}

[1] Lin Yufei. Cultivation Strategy of Intercultural Communicative Competence under Ubiquitous Learning Environment. Journal of Ningbo University, 2013. no.1. 
[2] Zhang Xiangyang. 20 Years Intercultural Communication Research in China: Review and Thinking. Foreign Language and Foreign Language Teaching, 2003. no.2.

[3] Zhang Hongling. Computer Network-based Intercultural Communicative Competence (CMICC) and Its Application in Foreign Language Teaching. Shandong Foreign Language Teaching, 2009. no.2.

[4] Wei Ling. Research on Intercultural Communicative Competence Cultivation System of College English and Practice. Open Education Research, 2012. no.1.

[5] Wang Qingwei. Intercultural Communicative Competence and Foreign Language Teaching. Liu Shengmin, Zhou Zhiyong. Foreign Language Teaching Research, Wuhan University of Technology Press, 2012.

[6] Zhang Weidong, Yang Li. Building of Intercultural Communicative Competence System_—Based on Foreign Language Education Perspective and Empirical Research Method. Foreign Language World, 2012. no.2. 